\title{
FUNDAMENTOS PARA PENSAR A INOVAÇÃO SUSTENTÁVEL
}

\section{FUNDAMENTALS TO THINK ABOUT SUSTAINABLE INNOVATION}

\author{
José Ernesto de Fáveri
}

Doutorado em fundamentos da educação pela USFCar. Grupo de Pesquisa Interdisciplinar em Ciências Humanas (CNPq) da Universidade do Contestado - Canoinhas, SC, Brasil, e-mail: faverije@gmail.com

\section{Resumo}

Este texto é uma proposta de reflexão aberta em torno dos fundamentos para compreender a inovação sustentável. Pretende ser uma reflexão no sentido de apontar que a sustentabilidade está vinculada diretamente a realidade objetiva em que o sujeito e a sociedade estão inseridos para produzir as coisas materiais para manter o ser humano vivo zelando pela preservação ambiental. Fora ou além dessa orientação de análise a sustentabilidade torna-se um discurso ideológico para ocultar a problemática da inovação ser um meio de predação do pensamento e das ações empreendidas pelo sistema de produção material predador do meio ambiente e da qualidade de vida individual e coletiva. O objetivo consiste em despertar o debate sobre a origem e o significado da autêntica forma de pensar a inovação compatível com preservação do meio ambiente, através de num sistema econômico ocupado e comprometido com o equilíbrio do planeta, no presente e no futuro. Essa abordagem está fundada em três pontos: o primeiro, uma contextualização e abrangência da temática; O segundo, consiste numa reflexão em torno da inovação, o terceiro, uma análise crítica sobre a sustentabilidade. Os três eixos estão interligados pelo vínculo essencial entre a inovação e a sustentabilidade.

Palavras-chave: Inovação, Sustentabilidade, Preservação, Consciência, Produção predadora.

\begin{abstract}
This text is a proposal for open reflection around the fundamentals to understand sustainable innovation. It intends to be a reflection in the sense of pointing out that sustainability is directly linked to the objective reality in which the individual and in society are inserted to produce as materials to keep the human being alive, ensuring environmental preservation. Outside or beyond this analysis orientation, sustainability becomes an ideological discourse to hide a problem of innovation being a means of predation of thought and actions undertaken by the system of predatory material production and individual and collective quality of life. The objective is to awaken the debate about the origin and the meaning of the automatic way of thinking about innovation compatible with the preservation of the environment, through the occupied economic system and committed to the balance of the planet, present and future. This approach is established in three points: the first, a contextualization and scope of the theme; The second consists of a reflection on innovation, the third, a critical analysis on sustainability. The three axes are interconnected by the essential link between innovation and sustainability.
\end{abstract}

Keywords: Innovation, Sustainability, Preservation, Consciousness, Predator production.

(C)UNIS-MG. All rights reserved. 


\section{INTRODUÇÃO: o contexto da abordagem}

O contexto de análise sobre a inovação sustentável reside em duas questões amplas: a formação do cidadão e a formação profissional como possibilidade de nascimento do sujeito da inovação. Só podemos pensar em formação profissional quando se pensa simultaneamente, a questão da formação do cidadão. A base comum para a dupla formação está ancorada na busca do conhecimento como instrumento que desenvolve concomitantemente, a habilidade de pensar que qualifica o indivíduo para o agir e vice-versa. Quando se forma o cidadão, coloca-se a base para a formação do futuro profissional, esse obviamente, busca a apropriação do conhecimento como instrumento para melhorar a atuação do homem sobre a realidade. Dessa forma, quando se melhora o conhecimento, melhora-se o fazer do profissional que representado no pensamento, produz para si o potencial de criar novas soluções para situações novas que vão dinamicamente aparecendo ao longo da vida. É nesse fluxo de ideias, ações e relações que se busca compreender a inovação sustentável.

De acordo com o exposto, temos aqui três dimensões fundamentais para iniciar esta reflexão: a formação do cidadão, a formação do profissional e o surgimento do sujeito de inovação. Obviamente, que essas dimensões estão interligadas como uma espécie de simbiose entre o sujeito que pensa e a prática que realiza. A prática enquanto a transformação do pensamento em experiência, começa na mais tenra idade e nos acompanha até o fim da vida. Portanto, a relação entre essas dimensões assume um caráter transversal porque tem como base o ser humano enquanto sujeito vivo capaz de produzir ações sobre a realidade e relações com os outros ao longo da vida no processo de produção material da existência. Isso rompe com o simples pertencimento ao mundo para entrar num processo de transcendência. Isto é, rompe com o momento e o ato isolado para entrar num processo dinâmico de transformação da realidade para melhor adaptá-lo a si. Por isso, inovação é um processo que envolve diretamente o pensar e o agir em busca da perfeição de ambos ao longo da vida.

A formação do futuro profissional está vinculada, diretamente, a formação do cidadão e, por conta disso, constrói o pensar de onde se origina novas ideias potencializadoras de novas ações. Um bom profissional para o momento atual, necessariamente, tem de ser um bom cidadão. O bom cidadão transforma- se num bom profissional. Dessa relação entre o cidadão e profissão surge o comprometimento do sujeito em pensar o que faz e fazer o que pensa, com o fim de transformar os problemas em soluções que ajudem o indivíduo e a coletividade a viver com dignidade buscando a plenitude do seu bem-estar material e "espiritual". ${ }^{1}$ Por isso, pensar em inovação sustentável representa uma reflexão em torno da relação entre a formação do cidadão e a formação profissional, ambos vinculados no processo de vida e em torno da realidade em que o sujeito está inserido. Esse pensar constrói visão de totalidade de si e da realidade mais próxima para empreender ações e construir relações para a construção da consciência do que somos e até aonde queremos chegar ao longo da vida, através da superação dos problemas ad hoc.

O sujeito de inovação está inserido nessa relação da formação do cidadão que se reflete na formação do profissional e vice-versa. É dessa relação que surge a condição humana de criar novas ideias e fazê-las funcionar na prática para construir uma significativa melhoria de vida nos indivíduos e das coletividades pela solução humana dos obstáculos que o mundo impõe para serem superados. Essa superação melhora a qualidade de vida para todos. Por isso, onde a maioria

\footnotetext{
${ }^{1}$ Significa ter acesso à cultura enquanto manifestação científica, estética e ética para elevar o nível de formação da consciência crítica, entendida como construção da visão de totalidade de si do mundo e da realidade na qual o indivíduo se encontra imerso.
} 
dos indivíduos percebe problemas, o sujeito de inovação tem de ter a capacidade de análise e compreensão do mesmo, para vislumbrar oportunidades possíveis.

\subsection{Abrangências da temática}

Toda essa abordagem está ancorada em compreender o significado e a importância do sujeito de inovação, ocupado com a vida e a preservação do planeta enquanto morada do ser humano.

A inovação não deve representar uma reflexão e ação unilateral que apenas aborde aspectos materiais e externos à vida das pessoas, mas acima e além de tudo, deve estar vinculada à preservação e o melhoramento das condições de vida e do meio. Isso significa cuidar de si e do mundo enquanto a morada em que o ser humano vive. O grande desafio da inovação, diante desse contexto apresentado, consiste em compreender a vida e o meio no sentido de construir uma visão holística ${ }^{2}$ de si e do mundo. O sentido de buscar essa compreensão consiste em encontrar o meio entre os extremos, do modo de produção material predadora da existência e o modo de produzir qualidade e dignidade para a vida pessoal e social do indivíduo. Esse é o ponto de partida e a base para começar a pensar em inovação sustentável. Nessa perspectiva, o processo material de produção da existência está, diretamente, integrado e interagindo com os processos individuais e sociais do viver e do conviver entre os seres humanos. A persistente busca desse equilibrado entre a produção material e a vida, sem qualquer tipo de agressão e dominação de um sobre o outro, produz a condição humana do bem-estar individual e coletivo do qual origina-se a humanização, tanto do ser humano como da sociedade. A sustentabilidade inspira harmonia em todas as dimensões e relações quando se trata da realidade existencial dos indivíduos e a satisfação cada vez mais elaborada de suas necessidades. Por isso, quando se cria uma nova ideia e essa é bem-intencionada no sentido de mirar uma ação boa, acaba adquirindo a qualidade de uma ideia boa, isto é, uma ideia que define uma ação produtiva e proativa, cujo o resultado é produzir qualidade de vida para o ser humano e para a sociedade, cujo o fim último é comprometer-se em cuidar de si e do meio em que vive.

Uma abordagem nessa perspectiva tem como finalidade abrir uma discussão e deixar a análise em aberto. Porque inovação é processo e não um ato isolado no sistema produtivo ou na vida das pessoas. É nessa direção que o debate, quanto mais intenso, mais estimula a curiosidade de aprofundar a temática, e, por isso, fica mais aberto por ser um debate que acompanha a dinâmica da evolução da civilização e da cultura. Quando nos remetemos a pensar em torno de temática tão ampla, como é nesse caso, a inovação sustentável acaba por se ancorar na vida individual e coletiva, onde se produz a existência e tudo o que se necessita para os indivíduos manterem-se vivos com dignidade. Aí, encontra- se o ponto de encontro entre inovação e sustentabilidade, originando-se a expressão inovação sustentável. Ou seja, a vida humana é o ápice e o centro de encontro entre produção material e preservação ambiental, para buscar a qualidade de vida individual e social. Uma reflexão, nessa perspectiva, que não tenha como preocupação fundamental a preservação e o melhoramento da vida, não faz sentido e será sempre uma abordagem unilateral, equivocada, predadora e ideologizada por valorizar uma dimensão e excluir outra. Pois, em vez de proporcionar uma condição para construir uma visão holística da vida com práticas cotidianas para melhorar o que somos, fazemos e o que vivemos,

\footnotetext{
2 Significa compreender os fenômenos na sua totalidade para superar a visão parcial e fragmentada de si e do mundo. Nesse ensaio, significa superar o falso e equivocado discurso parcial de que a inovação se restringe ao processo produtivo. Mas a visão holística abrange a compreensão global de si e do mundo para construir uma visão de totalidade que abrange o indivíduo, a sociedade e cuidado com o meio ambiente, enquanto dimensões de um todo articulado e dinâmico em que a vida se manifesta.
} 
enverada- se para uma abordagem ideológica, isto é, favorece um aspecto e exclui outros. $\mathrm{O}$ atual discurso sobre a sustentabilidade não consegue ir além do contexto produtivo e ideológico. Por isso, transforma-se em discurso ideológico porque favorece a produção capitalista predadora e exclui outros aspectos, como melhorar as condições de vida e a preservação do meio. Essa é uma visão empobrecedora, porque é uma compreensão restrita e isolada da sustentabilidade e se torna obstáculo para a construção da visão holística de si e do mundo. É preciso entender que a produção é uma dimensão, entre outras, que sustentam a vida e produz o desenvolvimento das coletividades com humanidade e equilíbrio. Portanto, Inovação não é discurso ideológico ou normas elaboradas, para impor um pensar e um agir; mas uma atividade de consciência, criadora de novas ideias que, colocadas em ação, possibilitam avanço nos processos de pensamento e na produção não predadora dos bens materiais de que o homem necessita para manter-se vivo. Enfim, pensar e viver são dois fenômenos muito próximos quando se pensa em inovação vinculada à sustentabilidade.

A sustentabilidade põe um freio à produção obsessiva e predadora com vistas apenas ao acúmulo de riqueza a qualquer custo. Preocupa-se, outrossim, com a preservação ambiental, cujo o fim último é melhorar as condições e os processos de vida dos indivíduos e da sociedade em geral.

O processo de inovação sustentável, entre outras dimensões, consiste em produzir ideias e pô-las em funcionamento sem agredir o indivíduo, a sociedade e o meio ambiente. Isso produz e fortalece as relações harmoniosas entre as diferentes dimensões da vida em que as ideias impactam nas diversas ações e relações sobre a realidade, em consequência da execução de projetos, previamente pensados e dinamicamente executados.

Tanto a inovação quanto a sustentabilidade, para serem vividas como ações e relações conscientes, estão profundamente ancoradas numa visão holística da vida e do mundo e jamais como atos isolados que se impõe aos indivíduos ou para atender setores da sociedade, objetivando atender interesses unilaterais de grupos econômicos minoritários da sociedade. É isso que dá origem ao discurso ideológico que impede o surgimento de práticas sustentáveis nos modos atuais de produção. Hoje, a sustentabilidade é mais um discurso midiático e de efeito passageiro, do que uma atitude consciente das ações e relações humanas em todos os contextos da vida. Enfim, a sustentabilidade é muito falada e pouco vivida nas sociedades capitalistas atuais.

Para construir uma visão Holística da vida, a reflexão tende estar alicerçada na pesquisa para entender como cada indivíduo, ao longo de sua vida e da espécie humana, consegue nos mais diferentes contextos culturais passar de estratégias pontuais para métodos na busca do aperfeiçoamento da sobrevivência; e passar dos métodos para teorias, e, consequentemente, passar de teorias para as invenções. Essas são frutos das ações e relações oriundas dos resultados de pesquisa, para fazer avançar o pensar e o agir, num mesmo processo de busca da resolução dos novos desafios. Esse é o significado de criar novas ideias e fazê-las funcionar na prática. Nessa perspectiva o pensar e fazer humano estão vinculados à realidade e a existência de onde se origina o sustento material e a cultural do homem contemporâneo.

Todo esse processo de busca da inovação para uma vida sustentável está ancorado em algo mais fundamental que é a concepção do ser humano. Daí surge uma questão fundamental: como é possível construir uma compreensão do ser humano, no momento presente, voltada para um mundo num ritmo acelerado de transformações? Sem dúvida, o ponto de partida para pensar e compreender essa questão antropológica é considerar o ser humano como a base de tudo. Isto é, o fundamento e o centro de toda atividade intelectual, construída desde um passado longínquo até os dias atuais, faz referência na busca de explicar a essência do ser humano. Um desses 
fundamentos apropriados para conceituar o ser humano nesse ensaio, encontramos no pensamento de Grabiel Marciel, quando conceitua o ser humano como o "Homo viator" que significa um ser viajante ou um ser em viagem. Portanto, o homem é um ser que se encontra numa situação de transitoriedade no mundo. Assim, temos o indicativo de que o homem é um ser de mudança, porque na medida em que a gerações vão se sucedendo, o ser humano vai transformando a realidade para melhor adaptá-la a si para satisfazer suas necessidades, a fim de manter-se vivo e se desenvolver. Nesse processo de busca da satisfação material para continuar vivo, o homem produz-se a si mesmo, porque desenvolve as operações mentais e, por conta disso, amplia e aprofunda a sua capacidade de pensar agregando conhecimento para si ao longo da vida. Esse modo de pensar nos induz a compreender que o ser humano é um ser que se constrói e constrói o mundo para si, ao longo e ao largo do processo de hominização ${ }^{3}$. O ser humano, imbuído pelo espírito inovador é alguém que representa a realidade no seu pensamento para construir projetos e empreender ações inéditas, visando superar situações novas e problemas relacionados à busca do melhoramento da qualidade de vida e preservação do meio. Com isso, sustentabilidade está relacionada com a vida do ser humano, no sentido de preservá-la e construir melhores condições de sobrevivência tanto do homem quanto na preservação planeta. A sustentabilidade, da mesma forma, está relacionada com o meio ambiente enquanto o contexto em que a vida se manifesta e se desenvolve. Portanto, a relação entre inovação e sustentabilidade é dupla, porque consiste simultaneamente, em cuidar da vida e do meio ambiente em que se desenvolve.

Para finalizar, um dos grandes desafios atuais da humanidade consiste em criar uma consciência coletiva de que os recursos naturais da terra são limitados e estão se esgotando cada vez mais rápido. A questão da água é um exemplo bem apropriado para ilustrar essa situação. Já existem disputas entre países e sociedade sobre o direito de represar os rios e córregos. Talvez uma alternativa para superar a crise hídrica no mundo seja investir menos no desenvolvimento de armas para realizar a guerra e, em contrapartida, investir mais nas técnicas de reciclagem da água para o uso do ser humano. Por isso, a inovação, dentro do processo de globalização atual, não pode significar apenas abertura dos mercados para a livre concorrência predadora das condições de vida e do meio ambiente, mas deve incluir o mínimo de fraternidade no sentido de criar entre os homens a capacidade de cuidar desses recursos naturais com maior consciência e responsabilidade. Isso vale para todos: sociedade, empresários, intelectuais, governantes prudentes e descentes. Para a preservação dos recursos naturais, necessitamos de menos leis e mais consciência sobre a preservação da vida no presente e no futuro, através de um manuseio consciente e responsável dos recursos naturais. As legislações e os direitos de explorar os recursos naturais devem ser revistos sob um ponto de vista ético e não apenas legal, com interesses políticos e econômicos. Por isso, precisamos de mais ética e menos legislação, pois, se a lei permite ser contornada, a ética, não. Não entender isso é defender uma inovação predadora da vida e dos recursos naturais.

\footnotetext{
${ }^{3}$ Significa o processo de construção da humanidade do homem pela formação de seu psiquismo mediante a produção dos bens de que necessita para sobreviver e manter-se vivo. Como consequência, cria-se a si próprio pela estruturação do pensamento que melhora o agir e o interagir, intencionalmente, planejado sobre o mundo para melhorar sua condição de vida e sua condição de sujeito pensante num processo sem fim, onde um, melhora o outro ao longo da evolução da espécie.
} 


\section{CONCEITO E OS FUNDAMENTOS ENTRE INOVAÇÃO E SUSTENTABILIDADE}

\subsection{0 conceito e os fundamentos da teoria de inovação}

Antes de mais nada, torna-se imprescindível deixar absolutamente claro que a concepção de inovação, aqui abordada, não é uma visão unilateral do utilitarismo material e nem do humanismo legal; mas uma abordagem que busca o equilíbrio entre os extremos da produção material predatória capitalista e a necessidade de produzir soluções sempre mais elaboradas, sem agredir e destruir a vida humana e o meio ambiente. Mediante essa preocupação, a humanidade exige práticas de inovação sustentáveis, ou seja, estimular processos de pensamento criador para a produção de bens materiais sem obsessão e dano à natureza. Isso implica abandonar o velho hábito de algumas minorias privilegiadas, que apenas pensam no acumulo de riqueza e pela busca desenfreada do lucro a qualquer preço, sem se importar com preservação ambiental e com o equilíbrio entre a natureza e o ser humano. O foco central da inovação sustentável é, e será sempre, a busca incansável na melhoria da qualidade de vida equilibrada para os indivíduos e as sociedades. Sem essa preocupação, pensar em inovação não faz nenhum sentido. A inovação sustentável está diretamente vinculada ao princípio do equilíbrio que supere os extremos do excesso e da falta. Os extremos são o anúncio de práticas obsessivas que induz à destruição. Por isso, a inovação só assume o caráter sustentável quando orientada por uma profunda motivação que estimule a capacidade criadora e também, a necessidade de uma consciência ética de todos com todos, no sentido de buscar o equilíbrio sobre a agir e interagir do homem ao longo da vida, satisfazendo necessidades humanas de manter-se vivo, sem qualquer tipo de agressão ou destruição do meio.

Uma vez esclarecida a postura aqui dotada, a reflexão e análise sobre a temática começa pelo entendimento do termo inovação. O vocábulo tem origem no latim "innovare", cujo o prefixo da palavra "in" tem o sentido de "em", e "novare" com significado "novo". Portanto, etimologicamente, inovação é o exercício da capacidade criadora do ser humano para enfrentar as situações novas que vai aparecendo ao longo da vida em diferentes situações, contexto e culturas. Assim sendo, a busca pela inovação não se situa no atual estágio de desenvolvimento da civilização. A inovação é um processo evolutivo que se iniciou desde os primórdios, isto é, num passado longínquo e que, devido aos avanços técnicos e tecnológicos, no momento atual se manifesta com mais intensidade e complexidade, anunciando que o futuro vai exigir ainda mais do ser humano, no sentido de desenvolver a habilidade de resolver desafios cada vez mais complexos. Por conta disso, há uma necessidade que o ser humano tenha cada vez mais criatividade, tanto no pensar, quanto no agir, como condição necessária para dar respostas eficazes e eficientes para situações e problemas novos que vão aparecendo.

Ao longo da história das civilizações, a capacidade de inovação, enquanto atividade criativa do ser humano, sempre esteve presente no sentido de transformar a realidade para adaptá-la a si para melhorar a qualidade de vida do homem. Tudo começa nos primórdios, quando o ser humano, com a incipiente capacidade racional, busca satisfazer as suas necessidades de sobrevivência, na conquista dos bens materiais para manter-se vivo. Nessa busca pela sobrevivência, além das operações sobre a realidade de manusear o mundo para si, desenvolve a capacidade de operações ideativas, responsáveis pelo desenvolvimento do pensar, condição essa para realizar atos inéditos e processos criativos, que transformam a realidade para melhorar gradativamente, o modo de satisfazer suas necessidades primordiais para continuar vivo. Com isso, ao mesmo tempo em que o homem busca a sua sobrevivência material de modo cada vez mais criativo e elaborado tecnicamente, desenvolve o pensar criativo, sempre aperfeiçoado pela criação anterior, como referência e impulso para dar continuidade à escalada progressiva para 
encontrar soluções novas e mais perfeitas para novos problemas que se impõe à vida humana. Por isso, a inovação não é um ato histórico isolado do passado, do presente e a especulação sobre o futuro, mas é um processo que "está sendo". Isto é, a inovação "não é", mas "está sendo", porque está embutida no processo histórico das civilizações para melhorar, evolutivamente, a vida dos indivíduos e das coletividades como um todo.

Nessa perspectiva, percebe-se a presença da capacidade inovadora do homem no passado, presente e como possiblidade no futuro. A inovação no passado é percebida nos procedimentos criativos que o ser humano realiza através de sua capacidade criadora sobre a realidade, com a clara intenção de superar os desafios e problemas pelos quais passava, na busca mais elaborada pela sobrevivência. Em qualquer momento do passado, percebe-se as pegadas do ser humano sobre a realidade pela produção dos artefatos que geram os mentefatos, onde o fazer e o pensar já estavam presentes num passado longínquo, pela busca da sobrevivência; no momento presente, o ser humano encontra-se diante de outros desafios e problemas ainda mais complexos, se comparados com a etapa anterior. Por sua vez, exigem do próprio homem um maior investimento de energia intelectual e desenvolvimento do potencial de criatividade pessoal para melhorar as condições atuais da vida, mediante a resolução dessas situações novas que o momento e o contexto atual exigem. Diante do quadro, o avanço da técnica e da tecnologia exige um melhor preparo do homem na criação dos artefatos técnicos e o seu manuseio para que haja mais eficiência e eficácia na produção dos bens materiais para manter-se vivo e viver com mais qualidade de vida. A ressalva que se faz é quanto ao uso inadequado e obsessivo desses artefatos técnicos, que comprometem a evolução do pensar e da racionalidade. Isso conduz o ser humano e a própria humanidade numa involução, tanto no pensar quando no agir. Penso que estamos diante de uma tragédia anunciada que é a crise social do conhecimento, que compromete a qualidade dos bens e serviços consumidos pelo ser humano. Isso representa a perda dos avanços que o ser humano realizou até o momento atual. No futuro, certamente, os desafios e os problemas, serão outros e, por isso, a solução exigirá um maior empreendimento de energia criativa e um pensar mais avançado para aperfeiçoar a busca de soluções dos problemas que irão surgir. A partir da visão holística do ontem, do hoje e do amanhã, podemos falar, sem delírios metafísicos, de criação do futuro. Em todos esses momentos, em grau de complexidade diferente, maior ou menor, o homem usa o máximo possível do seu pensar criativo, para encontrar, em cada época, dentro de suas condições e contextos específicos, a melhor solução para superar os problemas e desafios novos para aquele momento. Por isso, o pensar é a base para o processo de inovação 4 .

A grande dúvida que surge é: Será que hoje as instituições responsáveis pela formação dos cidadãos e dos profissionais do futuro, estão se preocupando, além do desenvolvimento de habilidades técnicas que a profissão exige, estimular simultaneamente, a formação de

\footnotetext{
${ }^{4}$ Daí não consigo entender porque nos cursos de graduação, a filosofia enquanto possibilidade de formação do pensar dos futuros profissionais e das futuras gerações é relegada ao segundo plano. A formação do atual profissional requer uma dupla e complementar formação entre o técnico e a formação do pensar. Quando uma dessas dimensões ficar comprometida no seu processo formativo, atrofia-se a prática do profissional, tornando-o um ser que age através de uma visão míope tanto do seu fazer quanto do seu pensar, comprometendo sua capacidade de inovação. Por isso, existe um discurso contraditório na universidade: fala-se em inovação e antagonicamente produz-se a domesticação pelo treino técnico, isto é, realiza a formação unilateral onde não estimula a reflexão que suscita o pensar criativo como condição para um agir inovador diante de novos desafios. Diante destas condições, a universidade torna-se uma indústria de produção de profissionais portadores da consciência ingênua e produz um profissional com um agir influenciado e viciado. Isto é, um agir mecânico sem condição alguma de representá-lo no seu pensamento para criar novas ideias. A habilidade de pensar não é desenvolvida pela escola e pela universidade comprometendo a possibilidade do trabalhador tornar-se um inovador no que faz.
} 
pensadores? A posição que se defende neste ensaio é a necessidade de realizar uma revisão crítica sobre o modo como está se formando o cidadão e o profissional do futuro e qual a contribuição da escola e da universidade para atingir esse fim. Talvez, seja o momento de refletir criticamente, em torno da possibilidade de organizar uma pedagogia ocupada e preocupada em como ensinar o indivíduo a pensar e, com isso, contribuir na construção do sujeito inovador preocupado com a sustentabilidade. Portanto, inovação sustentável implica construir na consciência do profissional no presente e no futuro comprometido, entre outras questões, a cuidar mais da vida e do futuro do planeta. Sem dúvida, isso requer menos concentração de riqueza para poucos e mais capacidade de repartir com a grande maioria. Essa é a primeira uma das condições fundamentais, para que o ser humano tenha acesso à informação e desenvolva para si a compreensão crítica ${ }^{5}$ da realidade em sua volta. Como consequência aprende a pensar mais, para ser mais sustentável no modo de agir e interagir nas sociedades atuais e no contexto em que vive. Isto é, criar condições de acesso à cultura ${ }^{6}$ e a formação com indicadores de construção de um pensar e agir equilibrado sobre o mundo e com os outros para preservar a vida e o meio.

Enfim, pensar que a inovação se restringe apenas no setor produtivo é uma forma equivocada, restrita e unilateral de concebê-la, porque inovar abrange todas as dimensões de vida individual e coletiva do ser humano por ser inerente ao processo de pensamento e de ação que o homem realiza, ao longo da história da civilização e no estágio atual que a humanidade se encontra. Por isso, o ser humano tem de ser compreendido na mais absoluta dimensão concreta, isto é, um ser em situação enquanto uma totalidade individual no coletivo. Esse conceito nos remete a necessidade atual de compreender que a inovação se origina da capacidade de um pensar criativo capaz de produzir novas ideias para gerar novos processos, sustentados em conhecimentos novos, isto é, criar novas ideias e fazê-las funcionar na prática. Por isso, tudo o que foi dito até aqui evidência que a inovação não é uma temática que se restringe a um campo do saber ou refere-se apenas a um setor da sociedade e da vida, mas é uma forma complexa de conceber o novo que faz avançar o poder ideativo do homem de criar e recriar soluções para situações novas quem vão aparecendo ao longo da existência. Isto implica em superar a visão unilateral da produção material da existência predatória que favorece as minorias sociais e exclui a ampla maioria em uma dada sociedade. A inovação está em tudo o que o ser humano realiza concretamente, para melhorar o contexto para si e viver com uma qualidade de vida sempre superior. Esse é um direito de todos e um dever ético dos sistemas econômicos preocupados com o bem-estar do indivíduo e da coletividade pela satisfação de suas necessidades.

\section{Qual o fundamento em que se sustenta a teoria da inovação?}

Como vimos anteriormente, as inovações estão presentes nos vários contextos culturais e na história da humanidade, ou seja, desde o momento que o ser humano se percebe autor de atos inéditos que os demais seres vivos de outras espécies eram incapazes de realizar. O ser humano é o único ser vivo que trabalha para adaptar o mundo para si e, dessa forma, melhorar

\footnotetext{
${ }^{5} \mathrm{O}$ conceito de compreensão crítica tem de ser entendido como a construção de uma visão de totalidade de si e da realidade em que se desenvolve a vida. Enfim, é compreender o que não é dito sobre a realidade para camuflar a verdade sobre ela.

${ }^{6}$ A ideia central, para compreender a cultura, reside no vínculo entre a produção da existência e a produção de si próprio. A produção da existência está centrada na capacidade que este ser tem de operar sobre o mundo para produzir os bens materiais que necessita para manter-se vivo, dentro de uma crescente e persistente busca da qualidade superior de vida. Por isso, é capaz de criações inéditas. Mas, simultaneamente, a esse processo, o homem é um bem de produção de si próprio, porque na medida em que opera sobre o mundo a fim de conseguir as coisas materiais para a sua sobrevivência, estrutura o pensamento, pelo fato de representar tais operações concretas, em forma de ideias cada vez mais perfeitas no seu pensamento. A cultura se manifesta como criação científica, estética e ética.
} 
qualitativamente a sua vida pela satisfação cada vez mais sofisticada das necessidades para manter-se vivo. Os demais seres vivos, de outras espécies, apenas se adaptam as condições que a natureza lhes oferece para sobreviver. É essa capacidade do ser humano de operar sobre a natureza e, simultaneamente desenvolver o pensar que produz o processo de inovação enquanto capacidade de criar novas soluções diante de novos desafios que surgem.

A tese fundamental para a compreensão do processo de inovação está alicerçada na capacidade que o ser humano tem de criar novas ideias e pô-las em funcionamento para gerar processos e produtos novos. Para criar novas ideias é necessário o exercício do pensar vinculado à realidade que, compreendida no seu real estado, gera novas ideias no pensamento. A ideia significa uma construção humana oriunda da representação da realidade no próprio pensamento do indivíduo. Desta forma, a ideia é uma força do pensamento que impele o homem realizar a ação. Nesse caso, a ideia está diretamente vinculada à ação humana, que num processo sem fim, melhora simultaneamente, o pensamento e as ações que realiza sobre a realidade em que o sujeito de inovação está inserido.

Nesta perspectiva a ideia significa um bem de produção do pensamento humano, capaz de gerar ações para superar problemas que a realidade nos impõe. No processo de transformar a ideia em ação, nasce o sujeito de inovação e desenvolve o processo de inovação com ações, cada vez mais dinâmicas e perfeitas. Isto é, uma vez materializada a ideia, sempre surgirão novos aspectos em relação à ideia anterior. Isso significa que o processo de construção e reconstrução da representação que o homem é capaz de realizar do real, constrói e reconstrói seu agir de maneira mais perfeita e avançada para satisfazer suas necessidades.

A ideia como um bem de produção evolui no pensamento humano na medida em que o homem aperfeiçoa seu modo de operar sobre a realidade em que está inserido. Isso melhora, significativamente, sua capacidade de operar e amplia seu poder de pensamento. Nessa perspectiva, o homem cria o mundo material para si e, simultaneamente, evolui na sua capacidade criadora. O homem evolui e constrói a cultura no processo em que busca satisfazer suas necessidades básicas de forma cada vez mais criativa e perfeita. Enfim, a cultura significa capacidade de criação do ser humano sobre a realidade para adaptá-la a si.

A transformação da ideia em ação e a ação transformada numa nova ideia gera um processo dinâmico de aperfeiçoamento sem fim, tanto das ideias, quanto das ações. Através desse processo dialético, a ideia adquire um caráter de bem de produção, porque as ideias se dissolvem em forma de ações e, essas, reconstroem-se em forma de novas ideias. Nesse processo, surge a "cultura da inovação", porque cria novas soluções para situações e desafios novos que vão aparecendo. Então, cultura significa toda e qualquer criação humana capaz de sustentar a dinâmica de pensar e do agir humano no e com mundo em que se desenvolve a sua existência. Enfim, se não há inovação no pensar, as ações e os processos vitais não se renovam, como consequência, não melhora o mundo e nem a vida do indivíduo e a coletividade. Dessa forma, a inovação fica suplantada numa visão míope e unilateral. É nessa condição que se transforma em ideologia, isto é, muito fala e pouco vivida. Enfim, o discurso retórico não se constitui em ação consciente e equilibrada.

Insisto que as ideias transformam-se num bem de pensamento capaz de impulsionar o homem a construir para si um pensar dinâmico que une a ação com a reflexão num processo sem fim. Por isso, a ideia concebida nessa condição é um bem de produção porque não morre na cabeça de quem pensa, não se distancia da realidade e muito menos se transforma em ideologia; mas, no mesmo processo e esforço de pensar, conectado com a realidade e as necessidades da vida, transforma as ideias em ações e as ações produzem ideias novas, porque cria uma conexão 
representativa da realidade no pensamento e o pensamento transforma-se em ação sobre o meio em que estamos imersos. Nesse movimento dialético entre ideia e ação impulsiona o ser humano a realizar novas ações através das representações que o ser humano realizou no seu pensamento. Enfim, pensar e agir entram numa dinâmica de aperfeiçoamento progressivo.

A produção de novas ideias origina-se da interpretação das ações e da própria realidade, da qual surge uma nova representação do significado da ação no pensamento do homem. Por isso, a teoria da inovação adquire uma nova essência e uma nova forma, porque traz consigo algo de novo, tanto no pensar quanto no agir.

Portanto, sinteticamente, podemos afirmar que a inovação se preocupa com duas dimensões fundamentais do ser humano, estreitamente interligadas. De um lado, a formação do cidadão e, do outro, a formação profissional. Ambas estão encoradas no desenvolvimento da capacidade de pensar que gera ideias novas, que impactam em novas ações e novas relações, no sentido de reinventar o presente para construir um futuro com uma qualidade de vida individual e coletiva superior ao momento presente.

\subsection{O significado humano de sustentabilidade na teoria da inovação a partir do pensamento de Leonardo Boff ${ }^{7}$}

Para manter o foco da reflexão, torna-se necessário realizar uma observação geral. Para abordar o significado da sustentabilidade na inovação é preciso pensar como, historicamente, o ser humano resolve seus problemas. Quando se busca a resolução dos problemas humanos temos que ter o cuidado para não se criar outros. Torna-se necessário construir um processo contínuo de soluções, mais elaboradas tecnicamente, dos problemas existentes. Em particular, aqueles que afetam a vida e aqueles que possam surgir no futuro. Se os problemas não são resolvidos de forma razoável, poderão comprometer a evolução da cultura e da civilização num futuro próximo. A sustentabilidade, por conta desse processo dinâmico na busca de solução dos problemas que afetam a vida do homem, acompanha o mesmo ritmo na busca de harmonização do pensar e do agir humano no mesmo processo de existir. Por isso, a sustentabilidade vinculada à inovação não pode ser concebida como um momento e um processo isolado da existência, entre eles o processo produtivo dos bens materiais. Os problemas surgem ad hoc e são muito diversificados. A primeira coisa que fazemos é resolver o problema que está diante de nós. Porém, nenhum problema que afeta a vida pessoal e a coletividade encontra-se isolado no tempo e no contexto, mas de alguma forma está ligado a outros problemas mais específicos e gerais da humanidade. Na busca insistente para resolver o problema, descobrimos o melhor método para superá-lo e, na medida em que o problema se repete e com ele a solução pela aplicação do método, como consequência, constrói-se a teoria. Uma vez detendo o domínio das teorias que deram certo sobre a resolução de problemas, a gente tenta fazer coisas novas com aquele embasamento teórico construído. Esse é ponto de partida para abordar o significado humano da sustentabilidade no processo de inovação. Enfim, sustentabilidade na inovação é assumir uma atitude diante da preservação e o aprimoramento da vida e do mundo em que ela se desenvolve. Portanto, numa visão holística:

Sustentabilidade é toda ação destinada a manter as condições [...] que sustentam todos os seres, especialmente [...] a vida humana, visando sua continuidade e ainda atender as necessidades da geração presente e das futuras, de tal forma que o capital natural seja mantido e enriquecido em sua capacidade de regeneração, reprodução e coevolução ${ }^{8}$.

\footnotetext{
${ }^{7}$ Esta abordagem está alicerçada na obra de Leonardo Boff. Sustentabilidade: o que é: o que não é. Petrópolis, RJ: Vozes, 2012.

${ }^{8}$ BOFF, Leonardo. Sustentabilidade: o que é - O que não é. Petrópolis: Vozes, 2012, p. 107.
} 
Diante de uma concepção tão ampla, mas ao mesmo tempo capaz de gerar consequências práticas específicas, é imprescindível que tenhamos um cuidado especial quando se produz as coisas necessárias para o ser humano manter-se vivo. Nessa empreitada, temos que incluir, nessa ação de sobreviver, a busca do equilíbrio entre o presente e o futuro, pois a ação de hoje vai refletir positiva ou negativamente sobre o futuro e as novas gerações. Por isso, sustentabilidade é conseguir viver em harmonia com o meio ambiente e com os outros numa relação dinâmica e equilibrada, no processo de evolução tanto do homem como da natureza sem abrir mão da qualidade de vida. Esse viver com equilíbrio entre o ser humano e a natureza significa não comprometer o presente e nem o futuro para que a vida no amanhã possa ser igual ou melhor do que a de hoje.

Toda a ação pressupõe uma fundamentação. A busca pelo fundamento da ação significa reflexão filosófica sobre o tema inovação sustentável que é objeto dessa análise. Conforme já exposto anteriormente, a inovação origina-se do pensar vinculado à realidade, capaz de criar novas ideias, para gerar dinamicamente novas soluções aos problemas que vão surgindo num dado momento e contexto de vida dos indivíduos e da comunidade. Nessa perspectiva, podemos afirmar que inovação sustentável refere-se ao pensar bem-intencionado, no sentido de potencialização das ações prudente para construir uma vida descente. Isto é, ações que venham solucionar problemas que afetam negativamente a vida e o bioma ${ }^{9}$, sem causar qualquer dano ou efeito destrutivo ao meio como sustentáculo da vida. Por isso, a sustentabilidade tem origem na qualidade positiva e crítica do pensar que pode ser qualificado como um bem-pensar que define um bom agir, isto é, uma agir construtivo, positivo, proativo e equilibrado. Enfim, a qualidade do pensamento gera a qualidade da ação. Isso atribui a dimensão humana tanto no pensar quanto no agir. Essa coerência entre um e outro define o que somos e fazemos para satisfazer, progressivamente, com qualidade sempre superior, as necessidades do ser humano e da coletividade.

A visão de sustentabilidade que adotamos é dinâmica e complexa porque não se situa nos extremos: da singularidade ou da pluralidade, do passado ou do presente, do presente ou do futuro, do individual ou do coletivo, do pensar ou do agir; mas situa-se num movimento simbiótico que liga e religa qualquer extremo, num processo evolutivo sem fim de aperfeiçoamento, na busca equilibrada de soluções aos problemas que surgem como desafios a serem superados pela espécie humana, sempre com o cuidado especial de preservar a vida e o meio em que os indivíduos vivem e convivem. Entendida dessa forma, o conceito de sustentabilidade está vinculado numa relação direta e reversível entre o pensar e o agir inovador.

O conceito de sustentabilidade, neste ensaio, tem origem e base nas atitudes de conservar, proteger e fazer prosperar tanto a vida como o meio que define uma perspectiva positiva e próativa em relação a capacidade de cuidar de si e do mundo em que a vida se desenvolve. Essa forma de conceber a sustentabilidade está ancorada numa visão cosmológica e antropológica, definida como possibilidade e compromisso de superação da dominação obsessiva da natureza para colocá-la numa profunda simbiose de acolhimento das novas interações e das novas formas de busca da sobrevivência, com equilíbrio para todos os indivíduos e nações. Ou seja, a atitude consciente de cuidar do planeta transforma-se em projeto de inovação, que se sustenta e se compromete com a preservação do meio ambiente com um radical exercício da responsabilidade social. ${ }^{10}$ Como resultado desse conceito de sustentabilidade, origina-se a exigência de viver uma

\footnotetext{
${ }^{9}$ Significa, neste ensaio, um conjunto de ecossistemas do planeta que definem as condições para que os seres vivos de todas as espécies continuem o processo evolutivo que garanta a sua sobrevivência no estágio atual e futuro.

${ }^{10}$ Significa, neste ensaio, o compromisso consciente de todos com a preservação do meio ambiente e de todas as manifestações da vida, na diversidade de seres vivos que habitam nos ecossistemas do planeta. Enfim, é uma
} 
ética do humano vinculada ao universo enquanto um profundo respeito recíproco entre o indivíduo e a sociedade e, essa, com o planeta.

Essa visão holística da sustentabilidade visa o máximo possível de inclusão, no sentido de buscar a humanização do ser humano em sociedade e com o planeta. Isso requer algumas atitudes: a) garantir a continuidade da humanidade, que implica em controlar a capacidade de destruição do ser humano e do meio em que vive. Isto é, sustentar a vida humana com dignidade; b) atender às necessidades do ser humano através do acesso sábio e equilibrado dos bem materiais para manter-se vivo com dignidade e, com isso, continuar o processo de evolução dos seres vivos, entre eles o homem; c) promover a sustentação da atual geração para que as gerações futuras possam se beneficiar de uma vida melhor, porque hoje, além de garantir a sobrevivência, gerou-se condições melhores para as futuras gerações, isto é, preservar a vida presente para que a futura se consolide com maior qualidade e equilíbrio do que a atual geração; d) viver a paz nas múltiplas dimensões. Isso significa viver a paz consigo mesmo, com os outros, com o meio ambiente e com ausência de conflitos entre nações que geram o confronto e promovem a violência em larga ou restrita escala na humanidade, com um grande potencial de destruição dos seres vivos e do meio ambiente.

A sustentabilidade abrange algumas dimensões específicas ${ }^{11}$ quando nos referimos à preservação da vida e do planeta. São elas: A sustentabilidade ambiental, social e econômica.

a) A primeira dimensão é a sustentação ambiental correta em busca de equilíbrio entre a produção material e preservação ambiental. 0 discurso capitalista predador sobre o desenvolvimento é um discurso retórico e vazio, porque não menciona a proteção das condições da vida humana, que produz as coisas materiais necessárias para manter-se vivo e, muito menos, faz referência clara e explicita no comprometimento com a diminuição da emissão de níveis mais baixos de poluição e contaminação do meio que comprometem a qualidade da saúde dos seres vivos prioritariamente, do ser humano quando se trata da produção material da existência. ${ }^{12} \mathrm{Na}$ verdade, as empresas predadoras, apenas têm como finalidade a obsessão pelo lucro desenfreado, sem se importar com as ameaças sobre o aquecimento global para a sobrevivência da nossa civilização e da própria espécie humana. Nesse processo predador de produção está embutido o conceito parcial e míope de inovação. Por isso, quanto mais se degrada hoje, mais se compromete o futuro da espécie humana e do meio ambiente para as gerações futuras.

Diante desse quadro, quais as alternativas possíveis para se implementar, progressivamente, a sustentação ambiental correta vinculada à inovação? A primeira, buscar

responsabilidade coletiva para cuidar do mundo como morada das espécies vivas para protegê-las e conservá-las como condição para que continuem seu processo evolutivo.

${ }^{11}$ Ver BOFF, Leonardo. Sustentabilidade: o que é - O que não é. Petrópolis: Vozes, 2012, p. 44-48.

12 Não posso deixar de mencionar o descaso e o descompromisso do atual presidente dos Estados Unidos, Donald Trump em relação à preservação do meio ambiente e com a paz mundial. Numa viagem recente na segunda quinzena de maio/2017, em visita ao Oriente Médio e na sua participação na reunião do G7, na Itália, tenho de considerar e repudiar, do governo nacionalista xenófobo americano duas atitudes de grau significativo de irascibilidade: A Primeira, o negócio bilionário firmado com venda de armas à Arábia Saudita e em seguida pede paz no Oriente Médio. Veja a gritante contradição: o presidente quer a paz, mas se estimula a fabricação e venda de armas. Em sã consciência é possível aceitar tamanha contradição? A segunda atitude refere-se a participação no G7. $\mathrm{Na}$ oportunidade, recusa-se radicalmente, a assinar o tratado da França para diminuição da emissão da poluição do planeta. Essa postura deixa claro que apoia a produção predatória que consolida o descaso com a preservação do meio ambiente e com os biomas do planeta. Isso compromete o clima do planeta e piora a qualidade da saúde do planeta e da humanidade. Que indicativo temos para o futuro a curto, médio e longo prazo para a humanidade e o planeta? Você é a favor dessa política de produção capitalista predatória dessa natureza, a exemplo das empresas poluidoras americanas? 
juntamente com o progresso da ciência e da tecnologia a inclusão de estudos sobre a biodiversidade para criar uma consciência social sobre a preservação dos ecossistemas. Dessa forma, a ciência com essa preocupação e compromisso adquire a qualidade de ciência ecologicamente correta. Isto é, uma ciência que além do comprometimento com as novas descobertas científicas para resolver os problemas do ser do ser humano, ocupa-se em preservar o equilibro da vida e do meio em que as espécies vivas evoluem e se desenvolvem; a segunda, uma ciência, ocupada e preocupada com a preservação da biodiversidade, assume um caráter que fortalece a preocupação em superar os atuais índices de poluição do ar, da água e do meio em geral para proteger a saúde do ser humano e dos demais seres vivos de outras espécies, através da superação da contaminação química e poluição de toda a ordem, cujo fim é buscar o equilíbrio dos ecossistemas e da vida; a terceira estratégia consiste conservar e administrar os recursos naturais, renováveis e não renováveis para que as futuras gerações possam ter acesso a eles, para uma sobrevivência em condições mais dignas do que a nossa geração.

Por isso, o setor produtivo, ao realizar a gestão não predadora da produção material da existência, tem o compromisso de fazer a gestão da preservação do meio ambiente com atitudes eficientes e eficazes para melhorar a qualidade da saúde do ser humano, que se reflete na qualidade de vida das espécies como um todo. Portanto, quando se produz um design de um produto é necessário incluir nele a destinação correta dos resíduos, além de todas as prerrogativas de cuidado para não poluir, contaminar e degradar o meio, no momento de sua produção.

b) A segunda dimensão é a sustentabilidade socialmente justa. Essa consiste em superar o atual paradigma de produção e consumo como uma retórica para consolidar a visão de concentração da renda nas mãos de uma pequena minoria rural e urbana. Ou seja, os grandes latifundiários e as grandes empresas, que monopolizam a produção e o consumo via comércio, produzem as desigualdades socioeconômicas que definem uma sociedade que distribui as injustiças de toda a ordem, porque poucos têm muito e muitos têm pouco. É exatamente essa brutal relação de desigualdade que faz com que se instale o conflito que gera o confronto e, com isso, produz a violência em larga e restrita escala, quando se busca o acesso aos bens materiais para que o indivíduo e a sociedade possam manter-se vivos com dignidade.

De acordo com dados extraídos no IPEA (Instituto de Pesquisa Econômica Aplicada) em 2010, hoje, provavelmente, a situação se agravou com a atual governo Temer. Naquele ano constatou-se que $46 \%$ do PIB é controlado por apenas cinco mil famílias. Somente esse dado demostra que a desigualdade é brutalmente violenta e desumana na sociedade capitalista brasileira. Nessas condições, torna-se complicado fazer uma reflexão e análise sobre a sustentabilidade no setor socioeconômico brasileiro. Por isso, todo o mundo da produção capitalista é o mundo da opressão mais desumana.

Para superar esse vergonhoso quadro social e econômico desumano, algumas iniciativas podem reverter essa situação de desequilíbrio e de injustiça socioeconômica, consolidada pela classe mais rica e pelo governo do país, que insiste em consolidar políticas de Estado, responsáveis por gerar as desigualdades, a concentração de riquezas para pouco e distribui a pobreza para a maioria da população. Entre as principais alternativas, podemos citar: 1) garantir uma justa e equilibrada distribuição de renda para que a grande maioria da sociedade tenha acesso, mediante o resultado digno do seu trabalho, aos bens materiais e serviços para viver com dignidade e maior justiça social; 2) acesso à educação, saúde, com igualdade de oportunidade, trabalho digno, com o fim de melhorar a qualidade de vida individual e social das massas injustiçadas por um modelo econômico capitalista predador, explorador e selvagem; 3) democratização do acesso à cultura, de acordo com a compreensão anterior, enquanto estratégia de formação da consciência crítica e ecológica que determina um agir e interagir do indivíduo mais consciente e engajado, na luta por 
mudanças da situação de injustiça social que o brasileiro vive; 4) superar a condição desumana da pobreza como consequência da gananciosa concentração da riqueza nas mãos de poucas pessoas. Essa pobreza tem origem nas políticas econômicas de favorecimento à classes, empresarial, política e judiciária. O favorecimento da classe judiciária, realiza-se pela concessão de robustos salários, gerando dessa forma, sua participação na classe minoritária dos ricos que quanto mais têm, mais querem ganhar e possuir. Por isso, o rico é um ser agressivo, porque regressivo.

c) A terceira dimensão refere-se à sustentabilidade economicamente viável. Hoje, não existe um desenvolvimento econômico, mas um crescimento material pela modernização da indústria com o uso de tecnologias para produzir com maior rapidez possível e sem se importar com a depredação da vida e do meio para acumular renda e riqueza nas mãos de poucos. Essa é a essência de uma economia predadora, pois apenas se compromete com a lucratividade, enquanto modo de enriquecer os poucos donos de empresas que exercem o monopólio da produção nacional. "No mundo empresarial e dos negócios, o propósito é ganhar dinheiro com o menor investimento possível, com a máxima rentabilidade possível, com a concorrência mais agressiva possível e no menor tempo possível"13, sem comprometimento com a preservação da vida e do meio ambiente. Por isso, o mundo da produção predadora é o mundo da opressão desumanizadora do homem que trabalha.

Uma das estratégias para superar a economia, apenas preocupada com o crescimento material e, por isso predatória, seria implementar o desenvolvimento econômico viável, cuja a preocupação está centrada na sustentabilidade. Esse desafio, para ser vencido, implica em avaliar os impactos ambientais na instalação das novas empresas e adequar a produção combinada com a inovação consciente e comprometida com a preservação do capital natural, objetivando superar a ação predatória do setor produtivo. Outra estratégia para a superação do crescimento material é "a economia solidária como microssustentabilidade viável, [...] se apresenta como alternativa à economia capitalista, mais ainda, como uma economia pós-capitalista [...] movida pelos ideais éticos de preservação de todo tipo de vida e de criação das condições para o bem-viver de todos. Ela pode ser entendida, segundo Paul Singer, 'como um jeito de produzir, vender, comprar, consumir e trocar sem explorar, sem querer almejar vantagens e sem destruir a natureza'. Esse modelo se concretiza através das cooperativas de produção e consumo"14.

\section{CONSIDERAÇÕES FINAIS}

A relação entre inovação e sustentabilidade reside na capacidade de pensar a realidade para criar novas ideias no pensamento, que impele o ser humano a colocá-las em prática sem depredar a vida e o meio. A inovação é sustentável não somente na ação humana, mas quando, ao representar a realidade e os problemas, bem como os desafios, na forma de ideia no pensamento, está intencionando um tipo de ação consciente e comprometida com a causa da preservação da vida e do meio ambiente. Por isso, o bem-pensar gera o bem-viver. Isso se realiza quando a ideia, como intencionalidade do agir, é concebida com a qualidade de "bem-intencionada", no momento que vira ação sobre a realidade, por isso, assume o caráter de uma boa ação. Dessa forma, a ideia perde o caráter e a força predadora, e, ao se inscrever na realidade, assume a qualidade de ação equilibrada a favor do melhoramento da vida e a preservação do meio.

Outra relação a destacar entre inovação e sustentabilidade consiste em que ambas precisam ser entendidas como dimensão integradora entre pensar e agir, o presente e o futuro. Portanto é uma relação simultânea e reversível entre o trinômio, individuo/sociedade/meio

\footnotetext{
${ }^{13}$ BOFF, Leonardo. Sustentabilidade: o que é - O que não é. Petrópolis: Vozes, 2012, p. 44.

${ }^{14}$ BOFF, Leonardo. Sustentabilidade: o que é - O que não é. Petrópolis: Vozes, 2012, p. 60 e 61.
} 
ambiente, que se encontram dentro e fora de nós. Dentro, quando produzimos novas ideias e fora de nós, quando realizamos novas ações que constituem as novas reinvenções para superar os desafios e aperfeiçoar o indivíduo, a sociedade e a realidade em que se desenvolve a vida na geração do presente deixando para as gerações do futuro condições ainda melhores de vida, comparadas com as condições atuais.

A inovação sustentável é a formação da consciência holística sobre o que pensamos e fazemos, no momento presente, de forma equilibrada para deixar um legado às futuras gerações como ponto de partida e continuidade no cuidado com a vida e na preservação do meio como um continum entre o pensar e o agir equilibrado, como critério de verdade que ultrapasse o tempo e o contexto em que se desenvolve a vida. Portanto, empreender com consciência ecologicamente correta e o comprometimento com um futuro viável para as novas gerações é, também aprender. Isso significa aprender a cuidar de si e do mundo em que se desenvolve a vida com equilíbrio, sem prejudicar e destruir o ser humano, a sociedade e o meio ambiente.

\section{REFERÊNCIAS}

BOFF, Leonardo. Sustentabilidade: o que é - O que não é. Petrópolis: Vozes, 2012.

BOFF, Leonardo. Saber Cuidar: ética do humano compaixão pela terra. Petrópolis, RJ: Vozes, 1999.

CAPRA, F. A teia da vida. São Paulo: Cultrix, 1980.

FAVERI, José Ernesto de. O filosofar e a ética nas organizações: convite a reflexão e ação. 4.ed. Blumenau: Nova Letra, 2014.

FAVERI, José Ernesto de.FILOSOFIA DA EDUCAÇÃO: o ensino da filosofia na perspectiva freireana. 2.ed. Petrópolis: Vozes, 2011.

SILVA, C. Desenvolvimento sustentável: um modelo analítico integrado e adaptativo. Petrópolis: Vozes, 2006.

PINTO, Álvaro Vieira. Consciência e Realidade Nacional. Rio de Janeiro: MEC/ISEB, V.1 e V. 2, 1960. 